\title{
Serum levels of tumor necrosis factor -alpha and hsCRP in patients with breast cancer and correlation with histological parameters
}

\author{
Anisha Sharma1, Binita Goswami', Nikhil Gupta², Baidarbhi Chakraborty ${ }^{3}$ \\ ${ }^{1}$ Department of Biochemistry, Lady Hardinge Medical College, New Delhi, India, ${ }^{2}$ Department of Surgery, University College of Medical \\ Sciences, New Delhi, India, ${ }^{3}$ Department of Biochemistry, D Y Patil Medical College, Mumbai, India
}

\section{A B S T R A C T}

Background: Breast cancer is now the second most commonly cancer diagnosed in women after cervical cancer in India. Presentation at late stage further aggravates the problem. The outcome of breast cancer is usually determined by multiple factors. Aims and Objectives:This study was designed with the aim to investigate any correlation between serum tumor necrosis factor alpha and hsCRP in breast cancer with histological parameters of tumor behavior. Materials and Methods: A total of 30 histological confirmed cases of locally advanced breast cancer were enrolled for study. Total duration of study was two years. HsCRP was determined by solid phase direct sandwich ELISA method (Diaclone, France).Similarly TNF- $\alpha$ was also determined by Enzyme-linked immunosorbent method. Three-dimensional tumor size was determined radiologically through mammography. CT scan and MRI scan were taken at the time of diagnosis to detect metastasis. The data on tumor size, estrogen receptors status, lymph node status and TNM staging were reviewed and recorded. Results: Levels of TNF- $\alpha$ and hsCRP in patients with more advanced TNM staging, more advanced lymph node status and high histological grade were significantly raised. Similarly, their levels were significantly raised with increasing grade of adipose tissue invasion. Levels of TNF- $\alpha$ and hs CRP were also significantly raised in patients with estrogen receptor status positive whereas increase in levels of these markers was not significant in progesterone receptor status positive. Conclusion: Preoperative evaluation of tumor necrosis factor alpha and high sensitivity C-reactive protein may be valuable parameters for reflecting the severity of invasive breast cancer.

Key words: Breast cancer, Tumor necrosis factor alpha, CRP, Estrogen receptor, Progesterone receptor

\section{INTRODUCTION}

Breast cancer is one of the most common malignancies affecting about one in nine women. ${ }^{1}$ It is probably the most feared cancer in women because of its psychological impact. Nearly 1.3 million new cases are diagnosed every year worldwide. More recently the incidence of breast cancer has been observed to be increasing in low income countries and data suggests that over the next twenty years the majority of the increase in the worldwide burden of the disease will be due to rising incidences in these countries. It is estimated that by 2030 the global burden of breast cancer will increase to over 2 million new cases per year. ${ }^{2}$
Breast cancer is now the second most commonly cancer diagnosed in women after cervical cancer in India. National Cancer Registry Programme shows that in all urban areas of India breast cancer has now left cervical cancer behind and is the most frequently diagnosed cancer in women accounting for $25 \%$ to $33 \%$ of all cancers. Presentation at late stage further worsens the problem. ${ }^{3}$

The International Agency for Research on Cancer estimates that an approximately 80,000 women in India are affected by breast cancer each year and according to other agencies the number of cases of breast cancer in India is about 10,00,000 women each year. There will be 
approximately 2, 50,000 new cases of breast cancer in India by $2020 .^{4}$

Virchow noted the presence of leukocytes in neoplastic tissue and made a connection between cancer and inflammation. His hypothesis was based on the observation that tumors often arose at sites of chronic inflammation. ${ }^{5,6}$ Chronic inflammation plays an important role in various aspects of cancer involving cancer initiation, promotion, progression, metastasis and clinical features. ${ }^{7,8}$ Several possible mechanisms have been proposed for the relationship between cancer and the systemic inflammatory response. First, tumor growth or invasion could induce tissue inflammation. Second, tumor necrosis and hypoxia or local tissue damage might activate an inflammatory response. Third, cancer cells themselves could increase the production of inflammatory cytokines like TNF- $\alpha$, CRP, IL-6 and IL-8. These inflammatory cytokines and chemokines interact with the immune vascular system and facilitate cancer growth, invasion, and metastasis. ${ }^{9-11}$

C-reactive protein (CRP), a nonspecific marker of systemic inflammation, has been widely used to detect and monitor systemic inflammatory response in clinical practice and empirical research. ${ }^{12}$ Most studies suggested that CRP levels were higher in cancer cases than healthy subjects, and CRP levels for prediction of treatment efficacy and patients mortality with various types of cancer have been extensively reported. Whereas whether elevated CRP levels share an identical value in predicting future cancer incidence remains uncertain.

Tumor necrosis factor-alpha is a pleiotropic inflammatory cytokine. Most organs of the body appear to be affected by TNF- $\alpha$ and the cytokine serves a variety of functions many of which are not yet fully understood. The cytokine possesses both growth stimulating and growth inhibitory properties and it appears to have self regulatory properties as well. The cytokine is produced by several types of cells, but especially by macrophages. ${ }^{13}$

The outcome of breast cancer is usually determined by multiple factors. This study was designed with the aim to investigate any correlation between serum tumor necrosis factor alpha and hsCRP in breast cancer with histological parameters of tumor behavior.

\section{MATERIAL AND METHOD}

This prospective study was conducted by the collaborative efforts of the departments of Surgery, Biochemistry and Pathology, Maulana Azad Medical College and associated Lok Nayak Hospital and GB Pant Hospitals, New Delhi. The study population comprised of 30 cases of locally advanced breast carcinoma recruited from the surgical outpatient department. Pregnant and lactating patients were excluded from the study population. The study was commenced following detailed patient consent and clearance by the institutional ethical committee.

The various parameters that were evaluated include detailed clinico-pathological profile and TNF- $\alpha$ and hsCRP levels. Clinical staging using TNM classification was performed in all enrolled patients and was based on all information available before first treatment. This included documenting tumor size (on USG), node status and metastatic workup including USG abdomen and chest X-ray. The American Joint Committee on Cancer (AJCC) TNM staging system was used for staging of the patients. Trucut biopsy was done for histopathological examination and hormone receptor status of tumor.

Blood samples were collected before start of any treatment. Five $\mathrm{ml}$ of blood was drawn from the antecubital vein of the patients after applying tourniquet to arm with 24 gauge needle in the morning. Venous blood was collected in a plain vial. Blood was centrifuged within $30 \mathrm{~min}$ and serum kept at $-80^{\circ} \mathrm{C}$ until analysis for the study parameters. TNF- $\alpha$ and hsCRP levels were quantitated by ELISA. After enrollment into the study, each patient underwent Modified radical mastectomy after receiving neoadjuvant chemotherapy (three cycles). Paraffin embedded Pathologic breast specimen was reviewed after hematoxylin and eosin staining. Tissue specimens were examined for the various characteristics indicative of tumor prognosis. These include evidence of invasion, tumor size, mitotic index, histologic grade, receptor status, axillary lymph node status and adipose tissue invasion. Nikon Labophat microscope with 409 objective was used to count mitotic figures and points were given as follows: 1 point, 0 to 5 mitosis per high power field; 2 points, 6 to 10 mitosis per high power field; 3 points $>11$ mitosis per high power field. Modified Scarff-Bloom Richardson grading was used and grade 1 to 3 were assigned according to differentiation of tumor. Estrogen, progesterone receptor and HER-2-Neu status were ascertained by staining the paraffin sections using monoclonal antibodies to ER, PR, and HER 2neu respectively. Adipose tissue invasion was graded with focal involvement as 1 and extensive involvement as 2 grading.

\section{Statistical analysis}

The quantitative variables were analyzed by non parametric Mann Whitney U test for two groups or by Kruskal Wallis test for more than two groups. Wilcoxan signed rank test was used to determine the statistical significance on different points of time within the same group. The categorical variables were analyzed by using Pearson ChiSquare test/Fischer's exact test in case when expected cell 
count was less than five. The Spearman rank correlation was determined to examine the correlation between two quantitative variables. P value B 0.05 (2 tailed) was considered to be statistically significant. The data was analyzed by using SPPS statistical software version 16.0

\section{RESULT}

Table 1 is the representation of the differing levels of TNF alpha and hsCRP according to the TNM staging in the study population. It is evident from the data that as the tumour advances according to TNM staging so do the levels of the inflammatory biomarkers. This highlights the inflammatory milieu that co exists with cancer in such patients.

Tables 2 and 3 demonstrate a linear correlation between increase in TNF, CRP levels with increasing lympho-vascular and adipose tissue invasion. A statistically significant difference can be discerned from the table. Levels of TNF- $\alpha$ and hs CRP in patients with more advanced TNM staging (TNF- $\alpha \mathrm{P}<0.05$, hsCRP $\mathrm{P}<0.001$ Table 1 ), more advanced lymph node status (TNF- $\alpha \mathrm{P}<0.05$, hsCRP $\mathrm{P}<0.001$ Table 2$)$ and high histological grade (TNF- $\alpha$ $\mathrm{P}<0.05$, hsCRP $\mathrm{p}<0.05)$ were shown to be significant.

Table 4 illustrates the difference in serum levels THF and CRP with difference receptor status of breast tumours. Levels of TNF- $\alpha(\mathrm{p} \leq 0.049)$ and hs $\mathrm{CRP}(\mathrm{p} \leq 0.04)$ were significantly raised in patients with estrogen receptor status positive as shown in Table 4 whereas increase in levels of

\begin{tabular}{|c|c|c|}
\hline $\begin{array}{l}\text { TNM stage } \\
\text { n (\%) }\end{array}$ & $\begin{array}{l}\text { Mean baseline } \\
\text { hsCRP (ng/ml) }\end{array}$ & $\begin{array}{l}\text { Mean baseline } \\
\text { TNF- } \alpha(p g / m l)\end{array}$ \\
\hline T3N1M0 20 (66.67) & $252 \pm 31$ & $150 \pm 43$ \\
\hline T4bN0M0 5 (16.67) & $326 \pm 31$ & $224 \pm 34$ \\
\hline T4bN1M0 2 (6.67) & $335 \pm 27$ & $233 \pm 32$ \\
\hline T4bN2M0 2 (6.67) & $375 \pm 32$ & $273 \pm 29$ \\
\hline $\mathrm{T} 4 \mathrm{dN} 2 \mathrm{M} 01$ (3.33) & 411 & 309 \\
\hline P val. ${ }^{*}$ & 0.000 & 0.008 \\
\hline
\end{tabular}

\begin{tabular}{|c|c|c|c|c|}
\hline $\begin{array}{l}\text { Involved } \\
\text { lymph nodes }\end{array}$ & $\begin{array}{l}\text { TNF- } \alpha \\
\text { (pg/ml) }\end{array}$ & p value & $\begin{array}{l}\text { hsCRP } \\
\text { (ng/ml) }\end{array}$ & $p$ value \\
\hline No & 117 & \multirow[t]{5}{*}{0.002} & 219 & \multirow[t]{6}{*}{0.001} \\
\hline N1 (1-3) & $139 \pm 25$ & & $241 \pm 31$ & \\
\hline N2 (4-9) & $145 \pm 35$ & & $247 \pm 25$ & \\
\hline N3 $(\geq 10)$ & $216 \pm 64$ & & $318 \pm 52$ & \\
\hline Histological & & & & \\
\hline Grade & & & & \\
\hline 1 & $151 \pm 43$ & \multirow[t]{3}{*}{0.005} & $253 \pm 32$ & \multirow[t]{3}{*}{0.005} \\
\hline 2 & $178 \pm 45$ & & $280 \pm 50$ & \\
\hline 3 & $237 \pm 57$ & & $339 \pm 52$ & \\
\hline
\end{tabular}

these markers were not significant in progesterone receptor status positive.

\section{DISCUSSION}

Long term inflammation leads to cancer development and even predisposes to carcinogenesis. Injury in any form triggers a sequence of events that constitutes the inflammatory response. The microenvironment changes that arise due to inflammation due to the tumor may affect neoplastic progression. ${ }^{14}$ Today, there are many studies supporting the hypothesis that inflammation plays an important role in predisposing the individual to cancer. It is found that underlying infections and inflammatory reactions are associated with majority of cancer cases. In many epidemiological studies, the role of chronic inflammation in the carcinogenesis process was examined through studies of pro-inflammatory and anti-inflammatory cytokines. ${ }^{15}$

Inflammation is an important mechanism that can remove the agent causing injury and initiate tissue repair by launching a well coordinated immune response. The body responds to pathogen by inflammatory mechanism coordinated blood borne delivery to injured tissues of cells and soluble mediators. After the removal of the invading pathogen and wound healing, inflammation subsides. However, an unresolved inflammation on account of any failure in the precise control of the immune response can continue to perturb the cellular microenvironment, thereby leading to alterations in cancer-related genes and posttranslational modifications in the key cell signaling proteins involved in cell cycle, DNA repair and apoptosis. ${ }^{16,17}$

Macrophages, mast cells and neutrophils can also support tumor development by leading to up-regulation of non-

\begin{tabular}{|c|c|c|c|c|}
\hline $\begin{array}{l}\text { Adipose tissue } \\
\text { invasion } \mathrm{n}(\%)\end{array}$ & $\begin{array}{l}\text { TNF- } \alpha \\
\text { (pg/ml) }\end{array}$ & $p$ value & $\begin{array}{l}\text { hsCRP } \\
\text { (ng/ml) }\end{array}$ & $p$ value \\
\hline \multicolumn{5}{|l|}{ Absent } \\
\hline $11(36.67)$ & $141 \pm 39$ & 0.0002 & $243 \pm 21$ & 0.001 \\
\hline $1+10(33.33)$ & $179 \pm 47$ & & $281 \pm 43$ & \\
\hline $2+9(30)$ & $233 \pm 58$ & & $335 \pm 56$ & \\
\hline \multicolumn{5}{|l|}{ Mitotic index } \\
\hline 1 point $19(63.3)$ & $164 \pm 40$ & 0.04 & $266 \pm 50$ & 0.03 \\
\hline 2 points $11(36.7)$ & $211 \pm 69$ & & $311 \pm 59$ & \\
\hline
\end{tabular}

\begin{tabular}{|c|c|c|c|c|c|c|}
\hline \multirow[t]{2}{*}{ Markers } & \multicolumn{2}{|c|}{$\begin{array}{c}\text { Estrogen } \\
\text { receptor status }\end{array}$} & \multirow[t]{2}{*}{$P$ value } & \multicolumn{2}{|c|}{$\begin{array}{l}\text { Progesterone } \\
\text { receptor status }\end{array}$} & \multirow[t]{2}{*}{$P$ value } \\
\hline & ER+(9) & ER-(21) & & PR+(9) & PR-(21) & \\
\hline TNF- $\alpha$ & $212 \pm 63$ & $128 \pm 47$ & 0.049 & $188 \pm 66$ & $178 \pm 49$ & 0.65 \\
\hline hsCRP & $314 \pm 56$ & $270 \pm 39$ & 0.04 & $290 \pm 37$ & $280 \pm 29$ & 0.8 \\
\hline
\end{tabular}


specific pro-inflammatory cytokines, such as interferon- $\gamma$, tumor necrosis factor (TNF), interleukin (IL) $-1 \alpha / \beta$ or IL-6. ${ }^{18,19}$ Likewise, activated nuclear factor- $x \mathrm{~B}(\mathrm{NF}-\varkappa \mathrm{B})$ transcription factor is one of the main links between inflammation and tumor genesis and may be key to allowing both pre neoplastic and malignant cells to escape from apoptosis. ${ }^{20,21}$

CRP is one of the most important proteins that is rapidly produced by hepatocytes during an acute-phase response upon stimulation by IL- $6, \mathrm{TNF}^{-} \alpha$ and IL-1- $\beta$ originating at the site of inflammation.CRP has a half-life of 19 hours that is independent of any physiological or patho physiological circumstances or of the concentration of CRP in the serum. Therefore, the synthesis rate of CRP by the liver is the only factor determining the plasma CRP concentration. $^{22}$

Numbers of prospective epidemiological studies have explored the elevated CRP levels in relation to an increased risk for cancer. Among them, most case-control studies have shown a higher cancer risk in people with elevated CRP level ${ }^{23-26}$ while, the findings from prospective cohort studies have been inconsistent. ${ }^{27-29}$ In our study also CRP levels were significantly high and increased with advancing TNM staging.

Tumor necrosis factor- $\alpha(\mathrm{TNF}-\alpha)$ is a pro-inflammatory cytokine involved in the promotion and progression of cancer. ${ }^{30}$ It plays an important role in the tumor microenvironment both as a membrane-integrated protein and in its soluble form generated after proteolytic cleavage. ${ }^{31}$ TNF- $\alpha$ stimulates many signaling pathways by binding to two receptors, TNFR1 (p55) and TNFR2 (p75). ${ }^{32}$ TNF receptor activation leads to the activation of multiple cell signaling cascades that lead to inflammation and survival of the tumor cells. Several studies have suggested that TNF- $\alpha$ plays an important role in the molecular events that link inflammation with development and evolution towards breast cancer. ${ }^{33}$

Number of studies has explored the role of TNF- $\alpha$ in relation to an increased risk for cancer. Among them, most case-control studies have shown a higher cancer risk in people with elevated TNF- $\alpha$ levels. ${ }^{34-36}$ Similarly in our study also increased levels of $\mathrm{TNF}-\alpha$ are associated significantly with advancing TNM staging.

\section{CONCLUSION}

Preoperative evaluation of tumor necrosis factor alpha and high sensitivity C-reactive protein may be valuable parameters for reflecting the severity of invasive breast cancer.

\section{REFERENCES}

1. Sanlon EF, Arthur I, Holleb MD, Gerald P, Murphy MD. Breast Cancer. In text Book of Clinical Oncology American Cancer Society; 1991:177-193.

2. Geoffery RH. Dietary fat and breast cancer risks. An epidemiologic perspective. Cancer; 1994;74:1078-1084.

3. Murthy NS, Chaudhry K, Nadayil D, Agarwal UK, Saxena S. Changing trends in incidence of breast cancer: Indian scenario. Indian J Cancer 2009;46:73-74.

4. Neevan dsouza DR, Murthy NS, Aras RY. Projection of Cancer Incident Cases for India -Till 2026. Asian Pac J Cancer Prev 2013, 14 (7), 4379-4386.

5. Balkwill F, Mantovani A. Inflammation and cancer: back to Virchow. 2001; 357: 539-45.

6. Mantovani A, Allavena P, Sica A, Balkwill F. Cancer-related inflammation. 2008; 454: 436-444.

7. Balkwill $F$, Mantovani A. Inflammation and cancer: back to Virchow; 357, 539-545.

8. Babu SN, Chetal G, Kumar S. Macrophage migration inhibitory factor: a potential marker for cancer diagnosis and therapy. Asian Pac J Cancer Prev 2012; 13, 1737-1744.

9. Balkwill F, Mantovani A. Inflammation and cancer: back to Virchow? Lancet 2001; 357(9255):539-545.

10. Heikkila K, Ebrahim S, Lawlor DA. A systematic review of the association between circulating concentrations of $C$ reactive protein and cancer. J Epidemiol Community Health 2007; 61: 824-833.

11. Roxburgh CS, McMillan DC. Role of systemic inflammatory response in predicting survival in patients with primary operable cancer. Future Oncol 2010; 6: 149-163.

12. Pearson TA, Mensah GA, Alexander RW. Markers of inflammation and cardiovascular disease: application to clinical and public health practice: A statement for healthcare professionals from the Centers for Disease Control and Prevention and the American Heart Association. Circulation 2003; 107: 499-511.

13. Murray J, Barbara J, Dunkley S, Lopez A. Regulation of Neutrophil Apoptosis by Tumor Necrosis Factor-Alpha: Requirements for TNF-R55 and TNF-R75 for Induction of Apoptosis In Vitro. Blood 1997; 90 (7): 2772-2783.

14. Noemi E, Francisco JV. Inflammation and cancer. World J Gastrointest Surg 2012; 4(3): 62-72.

15. Lorusso G, Ruegg C. The tumor microenvironment and its contribution to tumor evoluation toward metastasis. Histochem cell Biol 2008;130:1091-1103.

16. Mantovani A, Schioppa T, Porta C, Allavena P, Sica A. Role of tumor-associated macrophages in tumor progression and invasion. Cancer Metastasis Rev 2006; 25: 315-322.

17. Pollard JW. Tumour-educated macrophages promote tumour progression and metastasis. Nat Rev Cancer 2004; 4:71-78.

18. Aggarwal BB, Shishodia S, Sandur SK, Pandey MK, Sethi G. Inflammation and cancer: how hot is the link? Biochem Pharmacol 2006; 72: 1605-1621.

19. Robinson SC, Coussens LM. Soluble mediators of inflammation during tumor development. Adv Cancer Res 2005; 93:159-187.

20. Karin M. Nuclear factor-kappaB in cancer development and progression. Nature 2006; 25;441(7092):431-436.

21. Naugler WE, Karin M. NF-kappaB and cancer-identifying targets and mechanisms. Curr Opin Genet Dev 2008; 18: 19-26.

22. Vermeire S, Assche GV, Rutgeerts P. C-reactive protein as a marker for inflammatory bowel disease. Inflammatory Bowel Diseases 2004; 10:661-665.

23. Gunter MJ, Stolzenberg-Solomon R, Cross AJ, Leitzmann 
MF, Weinstein S, Wood RJ, et al. A prospective study of serum $\mathrm{C}$-reactive protein and colorectal cancer risk in men. Cancer Res 2006; 66:2483-2487.

24. Aleksandrova $K$, Jenab $M$, Boeing $H$, Jansen $E$, Bueno-deMesquita HB, Rinaldi S, et al. Circulating C-reactive protein concentrations and risks of colon and rectal cancer: a nested case-control study within the European Prospective Investigation into Cancer and Nutrition. Am J Epidemiol. 2010; 172: 407-418.

25. Chaturvedi AK, Caporaso NE, Katki HA, Wong HL, Chatterjee $\mathrm{N}$, Pine SR, et al. C-reactive protein and risk of lung cancer. J Clin Oncol. 2010; 28, 2719-2726.

26. Pine SR, Mechanic LE, Enewold L, Chaturvedi AK, Katki $\mathrm{HA}$, Zheng YL, et al. Increased levels of circulating interleukin 6 , interleukin 8, C-reactive protein, and risk of lung cancer. J Natl Cancer Inst 2011; 103, 1112-1122.

27. Il'yasova D, Colbert LH, Harris TB, Newman AB, Bauer DC, Satterfield S, et al. Circulating levels of inflammatory markers and cancer risk in the health aging and body composition cohort. Cancer Epidemiol Biomarkers Prev 2005; 14: 2413-2418.

28. Zhang SM, Lin J, Cook NR, Lee IM, Manson JE, Buring JE, et al. C-reactive protein and risk of breast cancer. J Natl Cancer Inst 2007; 99: 890-894.

29. Van Hemelrijck M, Holmberg L, Garmo H. Association between levels of C-reactive protein and leukocytes and cancer: three repeated measurements in the Swedish AMORIS study. Cancer Epidemiol Biomarkers Prev 2011; 20: 428-437.
30. Brown ER, Charles KA, Hoare SA, Rye RL, Jodrell DI, Aird RE, et al. A clinical study assessing the tolerability and biological effects of infliximab, a TNF-a inhibitor, in patients with advanced cancer. Oncol 2008;19:1340-1346.

31. Balkwill F. TNF- $\alpha$ in promotion and progression of cancer. Cancer Metastasis Rev 2006; 25:409-416.

32. Madhusudan S, Foster M, Muthuramalingam SR, et al. A phase II study of Etanercept (Enbrel), a tumor necrosis factor inhibitor in patients with metastatic breast cancer. Clin Cancer Res 2004;10:6528-6534.

33. Hwang JR, Jo $K$, Lee $Y$, Sung JB, Park YW, Lee JH. Upregulation of CD9 in ovarian cancer is related to the induction of TNF-a gene expression and constitutive NF-KB activation. Carcinogenesis 2012; 33:77-83.

34. Leek RD, Lewis CE, Whitehouse R, Greenall M, Clarke $\mathrm{J}$, Harris AL. Association of macrophage infiltration with angiogenesis and prognosis in invasive breast carcinoma. Cancer Res. 1996;56:4625-4629.

35. Ben-Baruch A. Host microenvironment in breast cancer development: Inflammatory cells, cytokines and chemokines in breast cancer progression: reciprocal tumor-microenvironment interactions. Breast cancer Res 2003; 5(1):31-36.

36. Chou FF. Serum concentration of tumor necrosis factor in patients with breast cancer.Breast Cancer Research and Treatment 1997; 43: 211-215. 